\title{
Dose dependent effect of statins on postoperative atrial fibrillation after cardiac surgery among patients treated with beta blockers
} Salima Mithani*1,2, Muhammad S Akbar1,2, Deborah J Johnson3, Michael Kuskowski ${ }^{6}$, Katherine K Apple ${ }^{5}$, Jana Bonawitz-Conlin ${ }^{5}$, Herbert B Ward 5 , Rosemary F Kelly ${ }^{5}$, Edward O McFalls ${ }^{3,4}$, Hanna E Bloomfield7, Jian-Ming Li ${ }^{3,4}$ and Selcuk Adabag 3,4,7

Address: ${ }^{1}$ Department of Internal Medicine, Veterans Affairs Medical Center, Veterans Drive, Minneapolis 55417, USA, ${ }^{2}$ Department of Medicine, University of Minnesota, Delaware St SE, Minneapolis 55455, USA, ${ }^{3}$ Division of Cardiology, Veterans Affairs Medical Center, Veterans Drive, Minneapolis 55417, USA, ${ }^{4}$ Division of Cardiology, University of Minnesota, Delaware St SE, Minneapolis 55455, USA, ${ }^{5}$ Division of Cardiovascular Surgery, Veterans Affairs Medical Center, Veterans Drive, Minneapolis 55417, USA, ${ }^{6}$ Geriatric Research Education Center, Veterans Affairs Medical Center, Veterans Drive, Minneapolis 55417, USA and ${ }^{7}$ Center for Chronic Disease Outcomes Research, Veterans Affairs Medical Center, Veterans Drive, Minneapolis 55417, USA

Email: Salima Mithani* - salima.mithani@va.gov; Muhammad S Akbar - muhammad.akbar@va.gov; Deborah J Johnson - deborah.johnson5@va.gov; Michael Kuskowski - michael.kuskowski@va.gov; Katherine K Apple - katherine.apple.1@gmail.com; Jana Bonawitz-Conlin - jana.bonawitzconlon@va.gov; Herbert B Ward - wardx020@umn.edu; Rosemary F Kelly - kelly071@umn.edu; Edward O McFalls - mcfal001@umn.edu; Hanna E Bloomfield - hannah.bloomfield@va.gov; Jian-Ming Li - jian-ming.li@va.gov; Selcuk Adabag - adaba001@umn.edu

* Corresponding author

Published: 4 November 2009

Journal of Cardiothoracic Surgery 2009, 4:61 doi: 10.1 | 86/1749-8090-4-6I
Received: 6 August 2009

Accepted: 4 November 2009

This article is available from: http://www.cardiothoracicsurgery.org/content/4/I/6I

(C) 2009 Mithani et al; licensee BioMed Central Ltd.

This is an Open Access article distributed under the terms of the Creative Commons Attribution License (http://creativecommons.org/licenses/by/2.0), which permits unrestricted use, distribution, and reproduction in any medium, provided the original work is properly cited.

\begin{abstract}
Background: Previous studies on the effects of Statins in preventing atrial fibrillation (AF) after cardiac surgery have shown conflicting results. Whether statins prevent $A F$ in patients treated with postoperative beta blockers and whether the statin-effect is dose related are unknown.
\end{abstract}

Methods: We retrospectively studied 1936 consecutive patients who underwent coronary artery bypass graft $(C A B G)(n=1493)$ or valve surgery $(n=443)$ at the Minneapolis Veterans Affairs Medical Center. All patients were in sinus rhythm before the surgery. Postoperative beta blockers were administered routinely ( $92 \%$ within 24 hours postoperatively).

Results: Mean age was $66+10$ years and $68 \%$ of the patients were taking Statins. Postoperative AF occurred in $588(30 \%)$ patients and led to longer length of stay in the intensive care unit versus those without $A F(5.1+7.6$ days versus $2.5+2.3$ days, $P<0.0001)$. Patients with a past history of $A F$ had a 5 times higher risk of postoperative AF (odds ratio 5.I; $95 \%$ confidence interval 3.4 to 7.7 ; $P$ $<0.000 \mathrm{I})$. AF occurred in $31 \%$ of patients taking statins versus $29 \%$ of the others $(p=0.49)$. In multivariable analysis, statins were not associated with $\mathrm{AF}$ (odds ratio (OR) $0.93,95 \%$ confidence interval $(\mathrm{Cl}) 0.7$ to I.2; $\mathrm{p}=0.59)$. However, in a subgroup analysis, the patients treated with Simvastatin $>20 \mathrm{mg}$ daily had a $36 \%$ reduction in the risk of postoperative AF (OR $0.64,95 \% \mathrm{Cl}$ 0.43 to $0.6 ; p=0.03$ ) in comparison to those taking lower dosages.

Conclusion: Among cardiac surgery patients treated with postoperative beta blockers Statin treatment reduces the incidence of postoperative AF when used at higher dosages 


\section{Background}

Postoperative atrial fibrillation (AF) occurs after 30-40\% of cardiac surgeries [1-3] and is associated with increased risk of stroke [2-5], longer hospitalization, higher cost [46] and greater risk of long-term mortality [7]. Beta blockers [8-12] and amiodarone [13-15] are known to reduce the incidence of postoperative AF after cardiac surgery but the effects of statins have been less conclusive [16]. While statin treatment appeared to lower the risk of postoperative AF in some initial observational studies [17-21] no benefit was noted in a recent, well-conducted cohort of $>4000$ patients [22]. In the only randomized clinical trial in this arena, Atorvastatin, started 7 days before cardiac surgery, was associated with a $>60 \%$ reduction in the incidence of postoperative AF among 200 patients undergoing coronary artery bypass graft (CABG) surgery [23]. However, the extraordinarily high AF rate $(\sim 60 \%)$ in the control group of this study was not representative of the experience at most centers [3,17-21]. Furthermore, beta blockers, which unequivocally reduce postoperative $\mathrm{AF}$, were not administered routinely after surgery and the number of patients undergoing concomitant valve surgery was small $(\mathrm{n}=41)$. Whether statin treatment prevents AF among patients receiving postoperative beta blockers is still unknown. Also, whether the statin effect on postoperative $\mathrm{AF}$ is dosage dependent is unclear. Thus, the aim of the present investigation was to fill these gaps in knowledge in a large cohort of patients undergoing CABG or valve surgery.

\section{Methods}

\section{Study population}

This study was approved by the human studies subcommittee of the Research and Development Committee of the Minneapolis Veterans Affairs (VA) Medical Center. Individual consent was waived. A total of 2207 patients underwent CABG or valve surgery (with or without concomitant CABG) at the Minneapolis VA Medical Center between February 1999 and November 2005. Of these, 271 patients were excluded because of permanent preoperative AF $(n=131)$ or missing/uninterpretable electrocardiograms (ECG). A total of 1,936 patients were included in the final analysis, including those with a previous history of $\mathrm{AF}$ who were in sinus rhythm at the time of surgery $(n=114)$.

\section{Data Collection}

Preoperative clinical variables, procedural details and laboratory test results were retrospectively abstracted from the patients' electronic medical records and the VA Continuous Improvement in Cardiac Surgery Program, which is an ongoing database of prospectively-collected data in all patients undergoing heart surgery within the VA system [24-27]. Pre and postoperative medications, including statins and beta blockers, were obtained from the VA pharmacy database and further confirmed by the clinician notes in the electronic medical records. The use of VA pharmacy refill data as a measure of actual medication use has previously been validated $[28,29]$. At our institution all preoperative medications are continued postoperatively and all patients receive beta blockers within 24 hours after surgery, unless contraindicated. The peri-operative ECGs were obtained from the ECG laboratory database at the Minneapolis VA Medical Center.

\section{Ascertainment of atrial fibrillation}

The primary outcome variable was development of $\mathrm{AF}$ within 30 days after the cardiac surgery. Postoperatively, cardiac rhythm was continuously monitored for the first 72 to 96 hours in the intensive care and the telemetry stepdown units. Subsequently, 12-lead ECGs were performed routinely on a daily basis and when clinically-indicated until patients were discharged from the hospital. A followup ECG was performed at 30-days after hospital discharge. All ECGs were interpreted by two physicians (ASM and MSA). Additional revisions were performed by a cardiologist (ASA) when necessary.

\section{Data analysis}

All statistical analyses were performed using SPSS (version 16). Distribution of variables in the study cohorts were summarized as mean + one standard deviation when normally distributed or median and interquartile range if skewed. We compared baseline characteristics of the statin treated and untreated patients, using $t$ test for continuous variables and likelihood ratio $X^{2}$ tests for categorical variables. Logistic regression analysis was used to determine the odds ratio (OR) of AF in association with statin treatment. Multivariable logistic regression models included the baseline differences between the statin and non-statin groups and predictors known to be associated with postoperative AF. Thus the predictor variables in our multivariable models were age, body mass index, prior history of $\mathrm{AF}$, chronic lung disease, diabetes mellitus, hypertension, left ventricular function, peripheral and cerebral vascular disease, smoking status, history of myocardial infarction, New York Heart Association functional class, beta blocker treatment status, calcium channel blocker treatment, digoxin treatment, cardiomegaly, surgical procedure, crossclamp time and statin treatment status. As a separate analysis a propensity score for taking statin was created for each patient using the variables that were different between the statin-treated and untreated groups. Multivariable models including the propensity score were created to assess the statin effect on AF.

Predetermined subgroup analyses were performed to assess statin effect in patients undergoing CABG surgery only and to investigate whether the AF incidence was 
related to the dosage of Statin. A p-value of $<0.05$ was considered statistically significant.

\section{Results \\ Patient Characteristics}

The baseline characteristics of the 1936 cardiac surgery patients in relation to preoperative statin treatment are outlined in Table 1. Mean age was $66+10$ years and risk factors known to be associated with postoperative AF were prevalent (Table 1). A total of 1322 (68\%) patients were treated with statins pre- and postoperatively. Of these, 1205 were taking Simvastatin (mean dosage $33+22 \mathrm{mg}$; range 5 to $80 \mathrm{mg}$ ). The patients receiving statin treatment were younger, had a higher prevalence of coronary risk factors and were more likely to undergo CABG in comparison to those not taking statins (Table 1). On the other hand, statin-untreated patients were more likely to have left ventricular dysfunction, cardiomegaly and symptoms of heart failure.

Of the 1936 surgical procedures, 1493 (77\%) were CABG only (Table 2). Postoperatively, 1778 (92\%) of the patients received beta-blockers within the $1^{\text {st }} 24$ hours after surgery.

\section{Postoperative AF}

A total of 588 (30\%) patients developed postoperative AF after a median 2 days (range 1 to 29 days) following cardiac surgery. Postoperative beta blocker use $(\mathrm{p}=0.01)$, cardiomegaly $(\mathrm{p}=0.01)$, and previous history of $\mathrm{AF}(\mathrm{p}=$ 0.001 ) were associated with AF. Patients with a previous history of AF had a 5 times higher incidence of postoperative AF (odds ratio 5.1; 95\% confidence interval 3.4 to 7.7; $\mathrm{p}<0.0001$ ) compared to those without a prior history. Patients who developed postoperative AF had a significantly longer length of stay in the Intensive Care Unit $(5.1+7.6$ days versus $2.5+2.3$ days, $\mathrm{p}<0.0001)$ than those who maintained sinus rhythm.

\section{Effect of Statins}

Postoperative AF occurred in $31 \%$ of statin-treated patients versus $29 \%$ of those not taking statins $(p=0.49)$. In multivariable analysis, after adjusting for the differences between the statin and non-statin groups and for predictors known to be associated with postoperative $\mathrm{AF}$

Table I: Baseline characteristics of the I,936 cardiac surgery patients included in the study

\begin{tabular}{|c|c|c|c|c|}
\hline & \multirow[b]{2}{*}{$\begin{array}{c}\text { All patients } \\
n=1936\end{array}$} & \multicolumn{2}{|c|}{ Statin Treatment } & \multirow[b]{2}{*}{$p$ value } \\
\hline & & $\begin{array}{c}\text { Yes } \\
n=1322\end{array}$ & $\begin{array}{c}\text { No } \\
n=614\end{array}$ & \\
\hline \multicolumn{5}{|l|}{ Clinical data } \\
\hline Age [years] & $66+10$ & $65+10$ & $67+10$ & 0.01 \\
\hline Male, \% & $99 \%$ & $99 \%$ & $99 \%$ & 0.46 \\
\hline $\mathrm{BMI}\left[\mathrm{kg} / \mathrm{m}^{2}\right]$ & $29.4+5.4$ & $30+5.4$ & $29+5.3$ & 0.03 \\
\hline Diabetes mellitus, \% & $34 \%$ & $35 \%$ & $30 \%$ & 0.03 \\
\hline Hypertension, \% & $60 \%$ & $81 \%$ & $73 \%$ & 0.001 \\
\hline Chronic lung disease, $\%$ & $23 \%$ & $22 \%$ & $26 \%$ & 0.06 \\
\hline Peripheral vascular disease, $\%$ & $30 \%$ & $30 \%$ & $30 \%$ & 0.90 \\
\hline Cerebrovascular disease, $\%$ & $22 \%$ & $22 \%$ & $21 \%$ & 0.49 \\
\hline Current Smoking, \% & $68 \%$ & $21 \%$ & $17 \%$ & 0.03 \\
\hline History of myocardial infarction, \% & $42 \%$ & $46 \%$ & $33 \%$ & $<0.0001$ \\
\hline History of heart surgery, $\%$ & $9 \%$ & $9 \%$ & $9 \%$ & 0.82 \\
\hline LV ejection fraction $<50 \%$, $\%$ & $41 \%$ & $42 \%$ & $47 \%$ & 0.05 \\
\hline NYHA heart failure class III/IV, \% & $35 \%$ & $33 \%$ & $39 \%$ & 0.01 \\
\hline History of atrial fibrillation, $\%$ & $5.7 \%$ & $6.3 \%$ & $4.6 \%$ & 0.13 \\
\hline Chronic kidney disease, \% & $3.7 \%$ & $11 \%$ & $13 \%$ & 0.53 \\
\hline Cardiomegaly, \% & $27 \%$ & $25 \%$ & $31 \%$ & 0.01 \\
\hline \multicolumn{5}{|l|}{ Preoperative medications } \\
\hline BetaBlockers, \% & $53 \%$ & $57 \%$ & $46 \%$ & $<0.0001$ \\
\hline ACE-I or ARB, \% & $72 \%$ & $73 \%$ & $69 \%$ & 0.59 \\
\hline Gemfibrozil, \% & $8 \%$ & $8 \%$ & $7 \%$ & 0.59 \\
\hline Calcium Chanel blocker, \% & $21 \%$ & $23 \%$ & $17 \%$ & 0.01 \\
\hline Amiodarone, $\%$ & $16 \%$ & $16 \%$ & $17 \%$ & 0.31 \\
\hline Diuretics, \% & $41 \%$ & $40 \%$ & $43 \%$ & 0.13 \\
\hline Digoxin, \% & $8 \%$ & $7 \%$ & $12 \%$ & $<0.0001$ \\
\hline
\end{tabular}

Continuous variables are expressed as mean + SD or median with interquartile range

Abbreviations: LV: left ventricular; NYHA:New York Heart Association; ACE-I: Angiotensin Converting Enzyme Inhibitor; ARB: Angiotensin Receptor Blocker;BMI: Body Mass Index 
Table 2: Details of the surgical procedures performed on the I,936 study patients

\begin{tabular}{|c|c|c|c|c|}
\hline & \multirow[b]{2}{*}{$\begin{array}{l}\text { All patients } \\
n=1936\end{array}$} & \multicolumn{2}{|c|}{ Statin Treatment } & \multirow[b]{2}{*}{$\mathrm{p}$ value } \\
\hline & & $\begin{array}{c}\text { Yes } \\
n=1322\end{array}$ & $\begin{array}{c}\text { No } \\
n=614\end{array}$ & \\
\hline CABG, $\%$ & $77 \%$ & $84 \%$ & $62 \%$ & $<0.0001$ \\
\hline Valve surgery, $\%$ & $12 \%$ & $7 \%$ & $23 \%$ & $<0.0001$ \\
\hline Combined CABG and valve surgery, $\%$ & $9 \%$ & $8 \%$ & $12 \%$ & $<0.0001$ \\
\hline Other surgical procedure, $\%$ & $2 \%$ & $1 \%$ & $3 \%$ & $<0.0001$ \\
\hline Off-pump surgery, $\%$ & $5 \%$ & $5 \%$ & $5 \%$ & 0.94 \\
\hline Urgent/emergent surgery, \% & $11 \%$ & $12 \%$ & $10 \%$ & 0.20 \\
\hline Ischemic time [minutes] & $92+40$ & $90+38$ & $95+42$ & 0.04 \\
\hline Total CPB time [minutes] & $|37+5|$ & $134+50$ & $140+53$ & 0.08 \\
\hline
\end{tabular}

Abbreviations: CABG: coronary artery bypass surgery; $C B P$ : Cardiopulmonary bypass

(full list under statistical methods), statin treatment was not associated with the risk of postoperative AF (odds ratio $0.93,95 \%$ confidence interval 0.7 to $1.2 ; \mathrm{p}=0.59$ ). Results were similar after performing propensity matching analysis, to adjust for baseline differences between the statin-treated and untreated groups. Results did not change when the analysis was limited to patients who underwent CABG only.

\section{Effect of Statin dosage}

The majority (91\%) of our statin-treated patients were taking Simvastatin. Of these 1205 patients treated with Simvastatin, 668 (55\%) were taking Simvastatin $<20 \mathrm{mg}$ daily versus 537 treated with a higher dosage. Notably, postoperative AF was less common among the patients taking a higher dosage of statins versus those taking $<20$ $\mathrm{mg} /$ day ( $28 \%$ vs. $34 \%$; $=0.03$ ). In multivariate analysis, the patients treated with statins $>20 \mathrm{mg}$ daily had a $36 \%$ reduction in the risk of postoperative AF (odds ratio 0.64, $95 \%$ confidence interval 0.43 to $0.6 ; \mathrm{p}=0.03$ ) in comparison to those taking Simvastatin $<20 \mathrm{mg}$ daily (results similar with propensity matching).

\section{Discussion}

The aim of this investigation was to assess whether statins prevented AF after CABG and/or valve surgery among patients who were treated with beta blockers in the immediate postoperative period. We found that postoperative AF ( $30 \%$ in our cohort) occurred more commonly in those with a previous history of AF and was associated with a longer length of stay in the Intensive Care Unit. There was a $36 \%$ reduction in postoperative AF among those who were treated with a higher dosage (i.e. > $20 \mathrm{mg} /$ day) of statins. However the incidence of postoperative AF was not influenced by low dose statin treatment.

There has been a recent interest in using statins for preventing postoperative AF after cardiac surgery, however, the clinical results are mixed. Initial cohort studies in this arena suggested that statin treatment was associated with a $40 \%$ to $50 \%$ reduction in the incidence of postoperative AF in patients undergoing CABG [17-21]. Further, in a small randomized clinical trial of 200 statin-naïve patients, Atorvastatin $40 \mathrm{mg}$, started 7 days prior to elective cardiac surgery, was associated with a $>60 \%$ reduction in the risk of postoperative $\mathrm{AF}$ in comparison to placebo [23]. However, there were some limitations in these studies. First, postoperative beta blockers were not routinely administered and their use was not uniformly reported. Second, only a few valve surgery patients were included. Third, the AF rate in the placebo arm of the only randomized clinical trial was extraordinarily high (57\%). Finally, the magnitude of benefit approaching 60\% is considered unusually high with present medical treatments. The positive findings in these studies were recently refuted by a well-conducted cohort study of $>4000$ consecutive patients undergoing CABG or valve surgery [22]. In this study, Virani et al. found that statin treatment did not influence the incidence of postoperative AF.

Our data shows that, when beta blockers are on board, higher doses of statins were required to reduce the incidence of postoperative AF. Previously, Lertsburapa et al [17] and Kourliouros et al [18] had also found that higher dose statins were associated with greater reduction in postoperative AF. While our statin-treated patients were predominantly taking Simvastatin, a combination of different statins were used in the other 2 studies suggesting that the statin-effect is not brand specific.

The most notable difference between the previous studies and the present investigation was the use of postoperative beta blockers. Indeed, $>90 \%$ of our patients were treated with beta blockers within 24 hours of cardiac surgery. Administering beta blockers after surgery reduce AF incidence and withdrawal of preoperative beta blockers is one of the strongest predictors of postoperative AF [8-12]. Thus, it is possible that the previous reports of substantial 
benefits with statins may have been confounded by suboptimal utilization of postoperative beta blockers, particularly in the early postoperative period.

Another notable difference between the current and past study cohorts was in the number of valve surgery patients included. Postoperative AF is more common after valve surgery. Further, in contrast to patients undergoing CABG, statins are not routinely clinically indicated in valve surgery patients. Thus, assessment of statin effect on postoperative $\mathrm{AF}$ is particularly important among these patients. Whereas, most previous studies were largely comprised of patients undergoing CABG, almost $25 \%$ of our cohort and $>30 \%$ of the study cohort by Virani et al. underwent valve surgery with or without concomitant CABG. We found no evidence of reduction in postoperative $\mathrm{AF}$ with statins in the subgroup of our cohort who had valve surgery.

There is suggestive evidence that statin treatment may reduce non-surgical AF among patients with coronary heart disease $[30,31]$. However, the mechanism remains unknown and randomized clinical trial data are lacking. Notably, in a large cohort study in which propensity scoring was utilized to adjust for the baseline differences between the statin and non-statin groups there was no effect on AF incidence [32].

One of the strengths of our investigation was the size of the study sample of nearly 2000 patients, of which 30\% developed postoperative AF. This large sample afforded us a greater statistical power to adjust for all of the measured differences between the statin vs. no-statin groups and the predictor variables that are known to be associated with postoperative AF. Routine use of postoperative beta blockers and inclusion of a substantial number of valve surgery patients are other notable strengths. On the other hand, this study also has some limitations. The inherent shortcomings of retrospective cohort study design, including baseline differences among study groups, cannot be completely avoided, by a large sample size and statistical adjustment for the multiple variables. Further, the findings in subgroup analyses, although pre-specified in this case, should be considered as hypothesis generating. Almost all of our study patients were male. Thus caution should be exercised in extending these results to women. Also, the duration of statin treatment was not known. It is possible that the effect of statins on $\mathrm{AF}$ is dependent upon the duration of statin-therapy.

\section{Conclusion}

In conclusion, in this large cohort of cardiac surgery patients who were routinely treated with postoperative beta blockers, $30 \%$ had postoperative $\mathrm{AF}$ associated with a longer stay at the intensive care unit. Higher dose (but not lower dose) statin treatment was associated with a $36 \%$ reduction in the risk of postoperative AF.

\section{Competing interests}

The authors declare that they have no competing interests.

\section{Authors' contributions}

ASM: Study design, data acquisition, analysis and interpretation of data, drafting and revision of manuscript and final approval. MSA: Study design, data collection, revision and final approval of manuscript. DJJ: Study design, data collection, revision and final approval of manuscript. MK: Data analysis and interpretation, revision and final approval of manuscript. KKA: Data collection, revision and final approval of manuscript. JBC: Data collection, revision and final approval of manuscript. HBW: Study design, interpretation of data, revision and final approval of manuscript. RFK: Study design, interpretation of data, revision and final approval of manuscript. EOM: Study design, interpretation of data, revision and final approval of manuscript. HEB: Study design, interpretation of data, revision and final approval of manuscript. JML: Study design, interpretation of data, revision and final approval of manuscript. ASA: Conception and study design, data acquisition, analysis and interpretation of data, drafting and revision of manuscript and final approval.

\section{Acknowledgements}

We are indebted to Ann Marie Bangerter, Katharine Rose Tallman for their efforts in data collection. Dr. Adabag is supported, in part, by VA Clinical Science R\&D Service (Grant no. 04S-CRCOE 00I), Washington, DC.

\section{References}

I. Echahidi N, Pibarot P, O'Hara G, Mathieu P: Mechanisms, prevention and treatment of atrial fibrillation after cardiac surgery. J Am Coll Cardiol 2008, 5 I:793-80I.

2. Creswell LL, Schuessler RB, Rosenbloom M, Cox JL: Hazards of postoperative atrial arrhythmias. Ann Thorac Surg 1993, 56:539-49.

3. Andrews TC, Reimold SC, Berlin JA, Antman EM: Prevention of supraventricular arrhythmias after coronary artery bypass surgery: A meta-analysis of randomized control trials. Circulation I99I, 84:236-244.

4. Hogue CW Jr, Creswell LL, Gutterman DD, Fleisher LA: Epidemiology, mechanisms, and risks: American College of Chest Physicians guidelines for the prevention and management of postoperative atrial fibrillation after cardiac surgery. Chest 2005, I 28:9S-I6S.

5. Mathew JP, Parks R, Savino JS, Friedman AS, Koch C, et al.: Atrial fibrillation following coronary artery bypass graft surgery: predictors, outcomes, and resource utilization. MultiCenter Study of Perioperative Ischemia Research Group. JAMA I996, 276:300-6.

6. Aranki SF, Shaw DP, Adams DH, Rizzo RJ, Couper GS, et al.: Predictors of atrial fibrillation after coronary artery surgery. Current trends and impact on hospital resources. Circulation 1996, 94:390-7.

7. Villareal RP, Hariharan R, Liu BC, Kar B, Lee VV, et al.: Postoperative atrial fibrillation and mortality after coronary artery bypass surgery. J Am Coll Cardiol 2004, 43:742-8.

8. Bradley D, Creswell LL, Hogue CW Jr, Epstein AE, Prystowsky EN, Daoud EG: American college of chest physicians guidelines for the prevention and management of postoperative atrial fibrillation after cardiac surgery. Chest 2005, I 28:39S-47S. 
9. Mathew JP, Fontes ML, Tudor IC, Ramsay J, Duke P, et al.: A multicenter risk index for atrial fibrillation after cardiac surgery. JAMA 2004, 29 I: 1720-1729.

10. Coleman Cl, Perkerson KA, Gillespie EL, Kluger J, Gallagher R, et al:: Impact of prophylactic post-operative beta-blockade on post-cardiothoracic surgery length of stay and atrial fibrillation. Ann Pharmacother 2004, 38:2012-20I6.

II. Connolly SJ, Cybulsky I, Lamy A, Roberts RS, O'brien B, et al:: Double-blind, placebo-controlled, randomized trial of prophylactic metoprolol for reduction of hospital length of stay after heart surgery: the beta-Blocker Length Of Stay [BLOS] study. Am Heart J 2003, I 45:226-232.

12. Ferguson TB Jr, Coombs LP, Peterson ED: Preoperative betablocker use and mortality and morbidity following CABG surgery in North America. JAMA 2002, 287:222I-2227.

13. Mitchell LB, Exner DV, Wyse DG, Connolly CJ, Prystai GD, et al:: Prophylactic Oral Amiodarone for the Prevention of Arrhythmias that Begin Early After Revascularization, Valve Replacement, or Repair: PAPABEAR: a randomized controlled trial. JAMA 2005, 294:3093-3100.

14. Guarnieri T, Nolan S, Gottlieb SO, Dudek A, Lowry DR: Intravenous amiodarone for the prevention of atrial fibrillation after open heart surgery: the Amiodarone Reduction in Coronary Heart [ARCH] trial. J Am Coll Cardiol 1999, 34:343-347.

15. Daoud EG, Strickberger SA, Man KC, Goyal R, Deeb GM, et al.: Preoperative amiodarone as prophylaxis against atrial fibrillation after heart surgery. N Engl J Med 1997, 337: I785-I79I.

16. Howard PA, Barnes BJ: Potential use of statins to prevent atrial fibrillation after coronary artery bypass surgery. Ann Pharmacother 2008, 42:253-8.

17. Lertsburapa K, White CM, Kluger J, Faheem O, Hammond J, Coleman $\mathrm{Cl}$ : Preoperative statins for the prevention of atrial fibrillation after cardiothoracic surgery. J Thorac Cardiovasc Surg 2008, I35:405-4II.

18. Kourliouros A, De Souza A, Roberts N, Marciniak A, Tsiouris A, et al.: Dose- related effects of statins on atrial fibrillation after cardiac surgery. Ann Thorac Surg 2008, 85:15I5-20.

19. Ozaydin M, Dogan A, Varol E, Kapan S, Tuzon N, et al:: Statin use before by-pass surgery decreases the incidence and shortens the duration of postoperative atrial fibrillation. Cardiology 2007, 107:1 | 17-21.

20. Mariscalco G, Lorusso R, Klersy C, Ferrarese S, Tozzi M, et al.: Observational study on the beneficial effect of preoperative statins in reducing atrial fibrillation after coronary surgery. Ann Thorac Surg 2007, 84: I I58-65.

21. Marín F, Pascual DA, Roldán V, Arribas JM, Ahumada M, et al:: Statins and postoperative risk of atrial fibrillation following coronary artery bypass grafting. Am J Cardiol 2006, 97:55-60.

22. Virani S, Nambi V, Razavi M, Lee W, Elayda M, et al.: Preoperative statin therapy is not associated with a decrease in the incidence of postoperative atrial fibrillation in patients undergoing cardiac surgery. Am Heart J 2008, I 55:54 I-545.

23. Patti G, Chello M, Candura D, Pasceri V, D'Ambrosio A, et al.: Randomized trial of atorvastatin for reduction of postoperative atrial fibrillation in patients undergoing cardiac surgery: results of the ARMYDA-3 [Atorvastatin for Reduction of MYocardial Dysrhythmia After cardiac surgery] study. Circulation 2006, I I 4: I455-6I.

24. Adabag AS, Rector T, Mithani S, Harmala J, Ward HB, et al.: Prognostic significance of elevated cardiac troponin I after heart surgery. Ann Thorac Surg 2007, 83: 1744-50.

25. Grover FL, Johnson RR, Shroyer AL, Marshall G, Hammermeister KE: The Veterans Affairs Continuous Improvement in Cardiac Surgery Study. Ann Thorac Surg 1994, 58: I845-5I.

26. Grover FL, Johnson RR, Marshall G, Hammermeister KE: Factors predictive of operative mortality among coronary artery bypass subsets. Ann Thorac Surg 1993, 56:1296-1306.

27. Grover FL, Hammermeister KE, Burchfiel C: Initial report of the Veterans Administration Preoperative Risk Assessment Study for Cardiac Surgery. Ann Thorac Surg 1990, 50:12-26.

28. Osterberg L, Blaschke T: Adherence to medication. N EnglJ Med 2005, 353:487-97.

29. Steiner JF, Koepsell TD, Fihn SD, Inui TS: A general method of compliance assessment using centralized pharmacy records: description and validation. Med Care 1988, 26:814-23.
30. Goldberger J], Subacius H, Schaechter A, Howard A, Berger R, et al:: Effects of statin therapy on arrhythmic events and survival in patients with nonischemic dilated cardiomyopathy. J Am Coll Cardiol 2006, 48: 1228-1233.

3I. Mitchell LB, Powell JL, Gillis AM, KehI V, Hallstrom AP, AVID Investigators: Are lipid-lowering drugs also antiarrhythmic drugs? An analysis of the Antiarrhythmic Versus Implantable Defibrillators [AVID] Trial. J Am Coll Cardiol 2003, 42:8I-87.

32. Adabag $\mathrm{S}$, Nelson D, Bloomfield H: Effects of statin therapy on preventing atrial fibrillation in coronary disease and heart failure. Am Heart J 2007, I 54: I | 40-1 I 45.
Publish with Bio Med Central and every scientist can read your work free of charge

"BioMed Central will be the most significant development for disseminating the results of biomedical research in our lifetime. "

Sir Paul Nurse, Cancer Research UK

Your research papers will be:

- available free of charge to the entire biomedical community

- peer reviewed and published immediately upon acceptance

- cited in PubMed and archived on PubMed Central

- yours - you keep the copyright 